\title{
Lesser trochanter avulsion fracture: a case report
}

\begin{abstract}
Male patient, 15 years old, football (soccer) player, complaining acute pain in left hip after a ball kick on a soccer game. The symptoms were: functional impairment, difficulty in walk, tenderness to inguinal palpation, inability of flexion and extension of the left hip. The x-ray showed an avulsion fracture of the lesser trochanter. The treatment included rest, analgesia and non-weight bearing. In 45 days, the patient was asymptomatic, and in 90 days, he had return to sports activities.
\end{abstract}

Keywords: Lesser trochanter, Avulsion fracture, Child athlete
Volume 10 Issue I - 2018

\author{
Marcos Laube Leite,' Eduardo Frois \\ Temponi, ${ }^{2}$ Rodrigo Santos Lazzarini ${ }^{3}$ \\ 'Department of Orthopedics and Traumatology, Fundacao \\ Hospitalar Sao Francisco, Brazil \\ ${ }^{2}$ Department of Orthopedics and Traumatology, Hospital Madre \\ Teresa, Brazil \\ ${ }^{3}$ Department of Orthopedics and Traumatology, Hospital Vila Da \\ Serra, Brazil
}

\begin{abstract}
Correspondence: Marcos Laube Leite MD, Ortovasc Av Coronel Jose Dias Bicalho, 25 I- B CEP 31275050, Sao Belo Horizonte, MG, Brazil, Email marcoslaube20@gmail.com
\end{abstract}

Received: July 19, 2017 | Published: January 09, 2018

\section{Introduction}

The lesser trochanter is a growth region type apophysis, where is attached the illiopsoas muscle. Avulsion fractures on this region are generally secondary to strenuous physical activities. ${ }^{1}$ Usually occurs in males on the 7 to 16 years old, with a peak of incidence on the age of 14 years old. It's incidence is low; however, with the increasingly participation of athletes on early age in high demand competitions, this kind of trauma has become more often. ${ }^{2,3}$ The signs and symptoms that may occur include: pain in the groin region, mainly on palpation; limitation of hip flexion and adduction, pain and difficulty walking. ${ }^{2-4}$ The definitive diagnosis is made with Plain radiographs in AP and hip basin. ${ }^{5,6}$ The preferred treatment is conservative, with analgesia rest and withdrawal of partial load at walking. ${ }^{7,8}$ The prognosis is good and the differential diagnosis must be performed to rule out pathological fracture secondary to metastasis. ${ }^{5}$

\section{Case report}

We report a patient male, 15 years old, football player, with a crippling pain in left hip after a kick in football match, following a difficulty walking, tenderness to palpation in groin region and inability of extension and flexion of the hip. The x-rays showed a fracture-avulsion epiphysiolysis of the lesser trochanter classified as a Salter-Harris type I (Figure 1). We stipulated conservative treatment including rest, analgesia and non-weight bearing initially, and after pain control, progressive partial load was introduced. After 45 days he was asymptomatic and could walk without crutches. In 90 days, the patient was free to return to his sports practices.

\section{Literature review}

The low incidence of this type of fracture is accompanied by a poverty data in the literature. In systematic search in the main search engines (pubmed, medline, cochraine and bireme) we found some papers about the subject. In one retrospective Canadian study, 1126 children with fracture of the proximal third of the femur, only in three, this kind of trauma was described. OBI NJ et al. ${ }^{9}$ reported in 2014, a rare case of bilateral avulsion fracture of lesser trochanter. ${ }^{9}$ Reviews on the subject recommended the nonsurgical treatment, with good results, even in avulsions where the displacement was significant. In the vast majority of citations the trauma mechanism was related to competitive sports. Green and gay, have cited the hyperextension with hip abduction as the main mechanism of trauma. ${ }^{6}$ In 1993 James g et al. ${ }^{10}$ reported similar case to that quoted in the present report. His follow-up was of 3 years describing patient return, without any sequel, to activities exercised before the trauma. ${ }^{10}$ The treatment adopted in the present case was just the same. Articles have cited the importance of differential diagnosis with pathologic fracture at the lesser trochanter, secondary to metastasis, being leukemia the main primary tumor. $^{5}$ Bed rest and treatment with cast were cited in historical articles, published before 1960. McKinney and collaborators have made a review of publications in English on the subject and, in none of them, surgical treatment was indicated. ${ }^{10} \mathrm{We}$ found in our research two authors indicating surgical treatment in cases whose evolution of conservative treatment has not been satisfactory. ${ }^{11-13}$

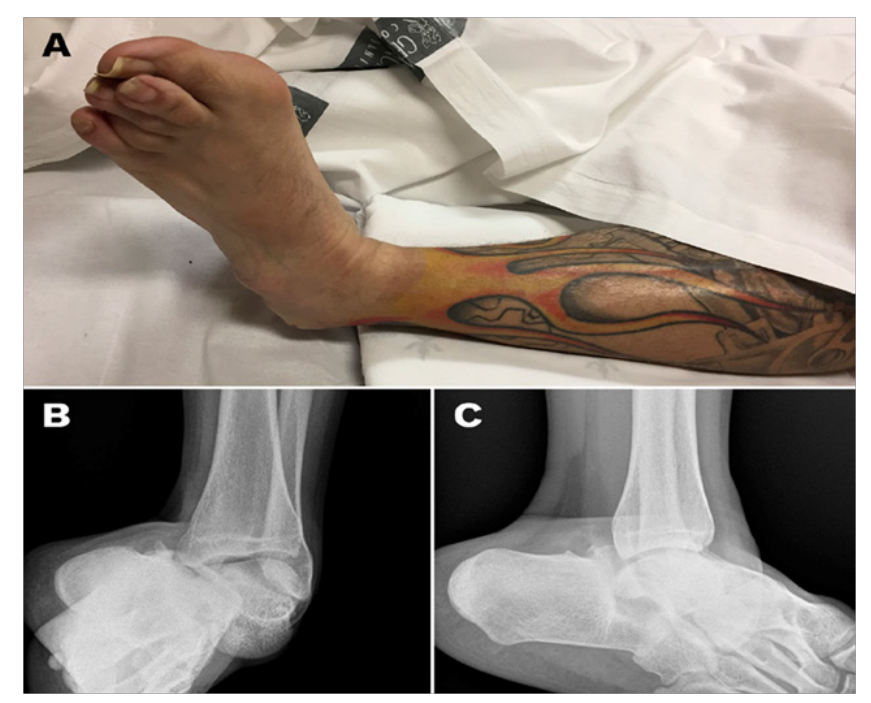

Figure I The x-rays showed a fracture-avulsion epiphysiolysis of the lesser trochanter classified as a Salter-Harris type I.

\section{Conflicts of interest}

The above authors declare that they do not have any potential conflict of interest in this study.

\section{Acknowledgements}

None. 


\section{References}

1. Dimon JH. Isolated fractures of the lesser trochanter of the femur. Clin Orthop. 1972;82:144.

2. Singh P, Kumar A, Shekhawat V, et al. Nonpathological Lesser Trochanter Fracture in Adult: Case Report and Brief Review of Literature. J Clin Res. 2015;9(11):RD04-5.

3. Nicholas C Papacostas, Christopher T Bowe, Tania D Shaffer Strout. Lesser Trochanter Avulsion Fracture. Journal of Emergency Medicine. 2013;45(2):256-257.

4. Max A Stevens, Georges Y, El-Khoury, et al. Imaging Features of Avulsion Injuries JA. Hip and pelvis avulsion fractures in adolescents. Physician Sports Med. 1994;22:41-49.

5. Bertin KC, Horstman J, Coleman SS. Isolated fracture of the lesser trochanter in adults: an initial manifestation of metastatic malignant disease. J Bone Joint Surg Am. 1984;66(5):770-773.

6. Green J, Gay F. Avulsion of the lesser trochanter epiphysis. Southern Med J. 1956;49:1308.
7. Fernbach SK, Wilkinson RH. Avulsion injuries of the pelvis and proximal femur. AJR Am J Roentgenol. 1981;137(3):581-584.

8. Theologis TN, Epps H, Latz K, et al. Isolated fractures of the lesser trochanter in children. Injury. 1997;28(5-6):363-364.

9. Obi NJ, Allman C, Moore-Thompson E, et al. Sequential bilateral lesser trochanter avulsion fractures in an adolescent patient. BMJ Case Rep. 2014;24:pii:bcr2014207911.

10. Gamble James G, Kao John. Avulsion Fracture of the Lesser Trochanter in a Preadolescent Athlete. Journal of Pediatric Orthopaedics. 1993.

11. McKinney BI, Nelson C, Carrion W. Apophyseal Avulsion Fractures w. of the Hip and Pelvis. Orthopedics. 2009;32(1):42.

12. The J. Avulsion of the lesser trochanter. Archives of Orthopaedic and Traumatic Surgery. 1978;91(1):81-83.

13. Khemka, Raz G, Bosley B, et al. Arthroscopically assisted fixation of the lesser trochanter fracture: a case series. J Hip Preserv Surg. 2014;1(1):27-32. 